\title{
N9 $9-10085$
}

\section{CONSOLE: A CAD TANDEM FOR OPTMMIATION-BASED DESIGN INTERACTING WITH USER-SUPPLIED SIMULATORS}

\author{
By \\ Michael K. H. Fan, LI-Sheng Wang. Jan Koninckx and Andre L. Tits \\ University of Maryland \\ College Park, Maryland
}

\begin{abstract}
The most challenging task when designing a complex engineering system is that of coming up with an approprlate system "structure." This task calls extensively upon the engineer's ingenulty, creativity, intuition and experience. After a structure has been (maybe temporarly) selected, it remains to determine the "best" value of a number of "design parameters." The engineer's Input is still essential here. as multiple tradeofls are bound to appear. However, except in the simplest cases, achleving anything close to optimal would be impossible without the support of numerical optimization. Providing such support while emphasizing tradeoff exploration through man-machine interaction is the purpose of interactive optimization-based design packages such as CONSOLE (Proceedings of American Control Conference 1988). A requirement for CONSOLE is that the parameters to be optimally adjusted vary over a continuous (as opposed to discrete) set of values.

CONSOLE employs a recently developed design methodology (International Journal of Control 43:1693-1721) which provides the designer with a congenial environment to express his problem as a multiple objective constrained optimization problem and allows him to refine his characterization of optimality when a suboptimal design is approached. To this end, in CONSOLE, the designer formulates the design problem using a high-level language and performs design task and explores tradeorf through a few short and clearly defined commands.

The range of problems that can be solved efficiently using a CAD tools depends very much on the ability of this tool to be interfaced with user-supplied simulators. For instance, when designing a control system one makes use of the characteristics of the plant, and therefore, a model of the plant under study has to be made avalable to the $\mathrm{CAD}$ tool. CONSOLE allows for an easy interfacing of almost any simulator the user has avallable.

To date CONSOLE has already been used successfully in many applications, including the design of controllers for a flexible arm and for a robotic manipulator and the solution of a parameter selection problem for a neural network (all under P. S. Krishnaprasad at the University of Maryland at College Park), the design of an RC controller for a radar antenna (under F. Emad at the University of Maryland at College Park). and the design of power fllters (at the Westinghouse Defense and Electronics Center). In the case of the neural network application. CONSOLE was coupled to the nonlinear system simulator SIMNON.
\end{abstract}




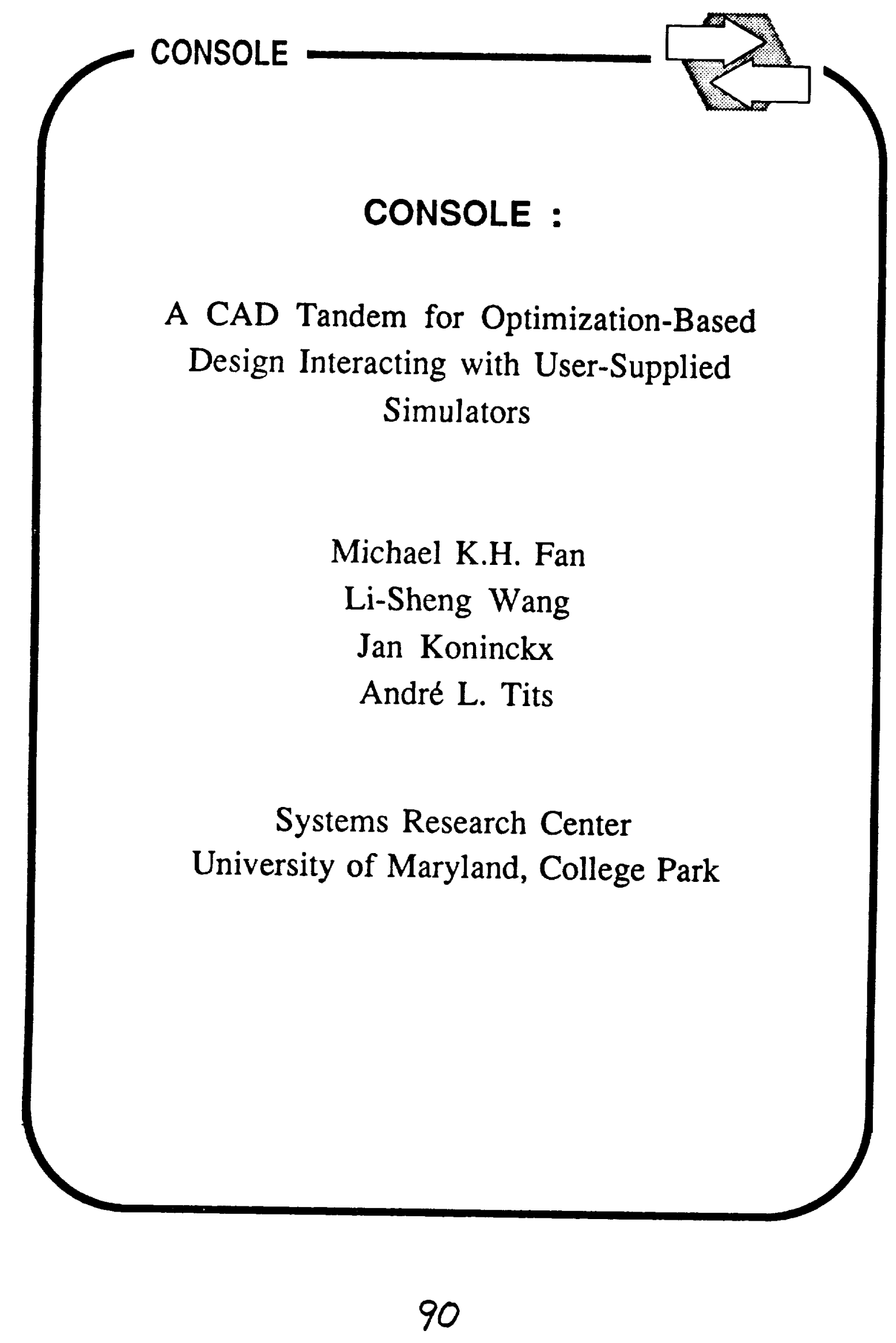




\section{CONSOLE}

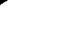

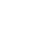

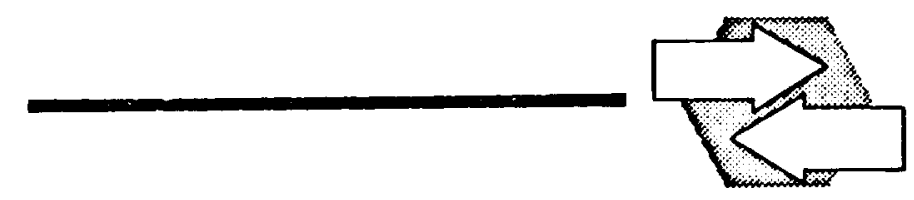

\section{HISTORY}

DELIGHT (Nye, Polak, Sangiovanni-Vincentelli, Tits) 1980 general purpose interactive package

+optimization algorithms

DELIGHT.MaryLin (Fan, Nye, Tits) 1985 -

interactive optimization-based design package for linear time-invariant systems

CONSOLE (Fan, Wang, Koninckx, Tits) 1987 interactive optimization-based design package for engineering systems (with user-supplied simulators) 


\section{CONSOLE}

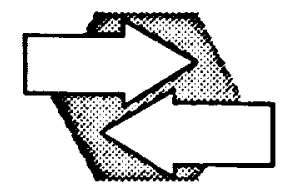

PARAMETRIC OPTIMIZATION IN DESIGN

Assume structure already chosen

Examples :

Circuit $\rightarrow$ Topology

Control System $\rightarrow$ Controller Structure

Earthquake Proof Building $\rightarrow$ Number and Position of Beams

Remain to choose best value of finitely many parameters Examples:

Circuit $\rightarrow R, C, W, A, \ldots$

Control System $\rightarrow$ Controller Gains, LQR/LQG Weighting Matrices, Q-parameterization, ...

Earthquake Proof Building $\rightarrow$ Beam Thickness, Amount of Steel, ... 


\section{CONSOLE}

\section{COMPONENTS FOR PARAMETERIC OPTIMIZATION}

1. Design Methodology (Nye, Tits)

Problem Formulation

Optimal in what Sense? Optimization Algorithm

$\rightarrow$ CONSOLE User-Machine Interaction

2. Model and Simulation Tool $\rightarrow$ Simulators

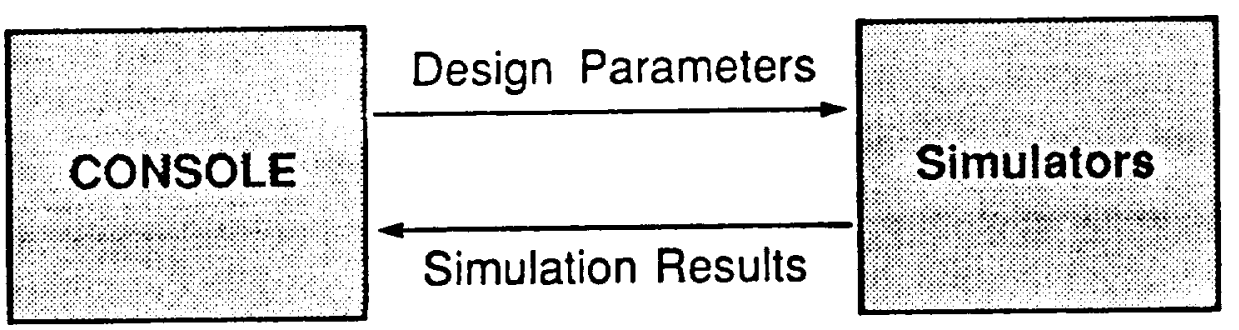




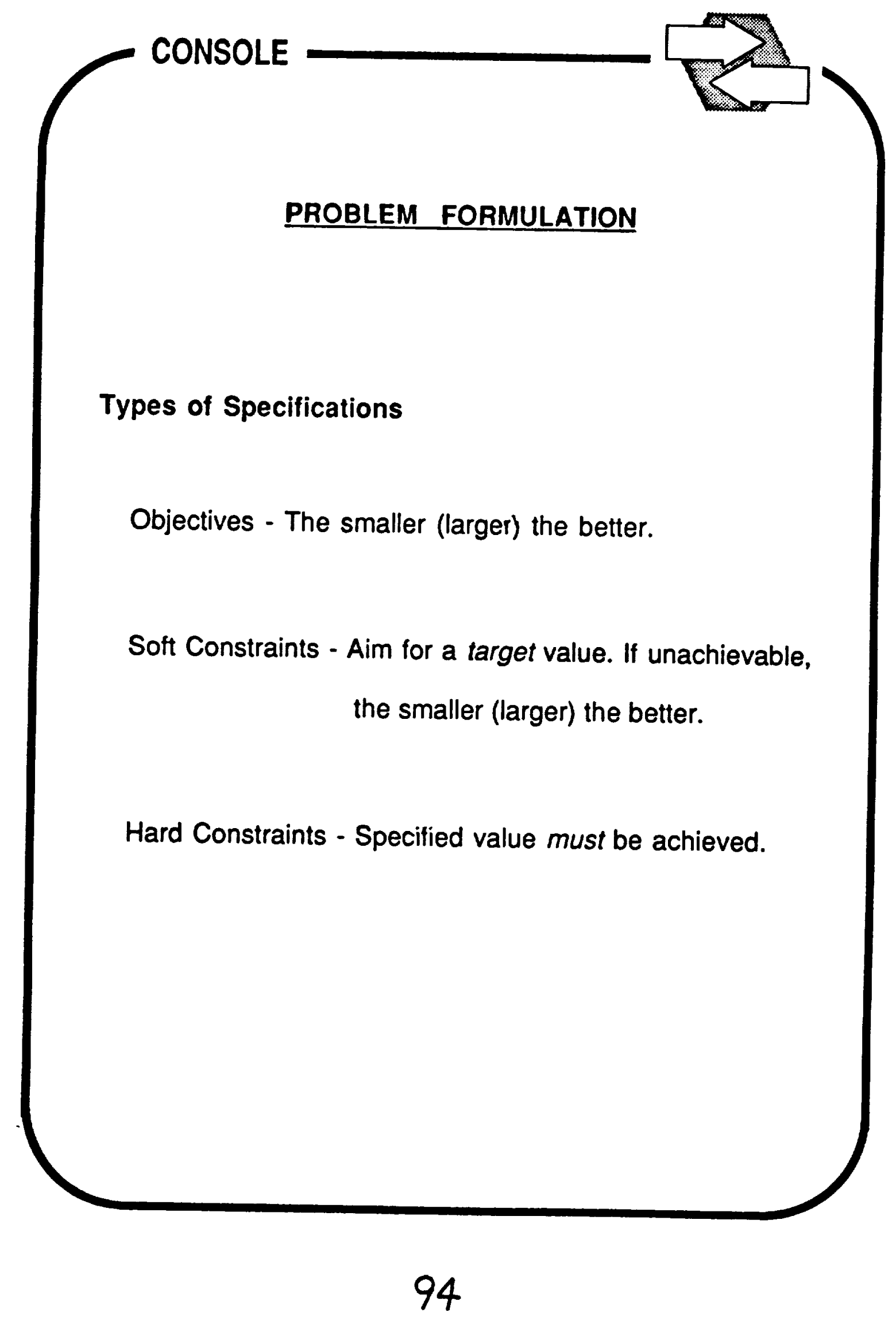




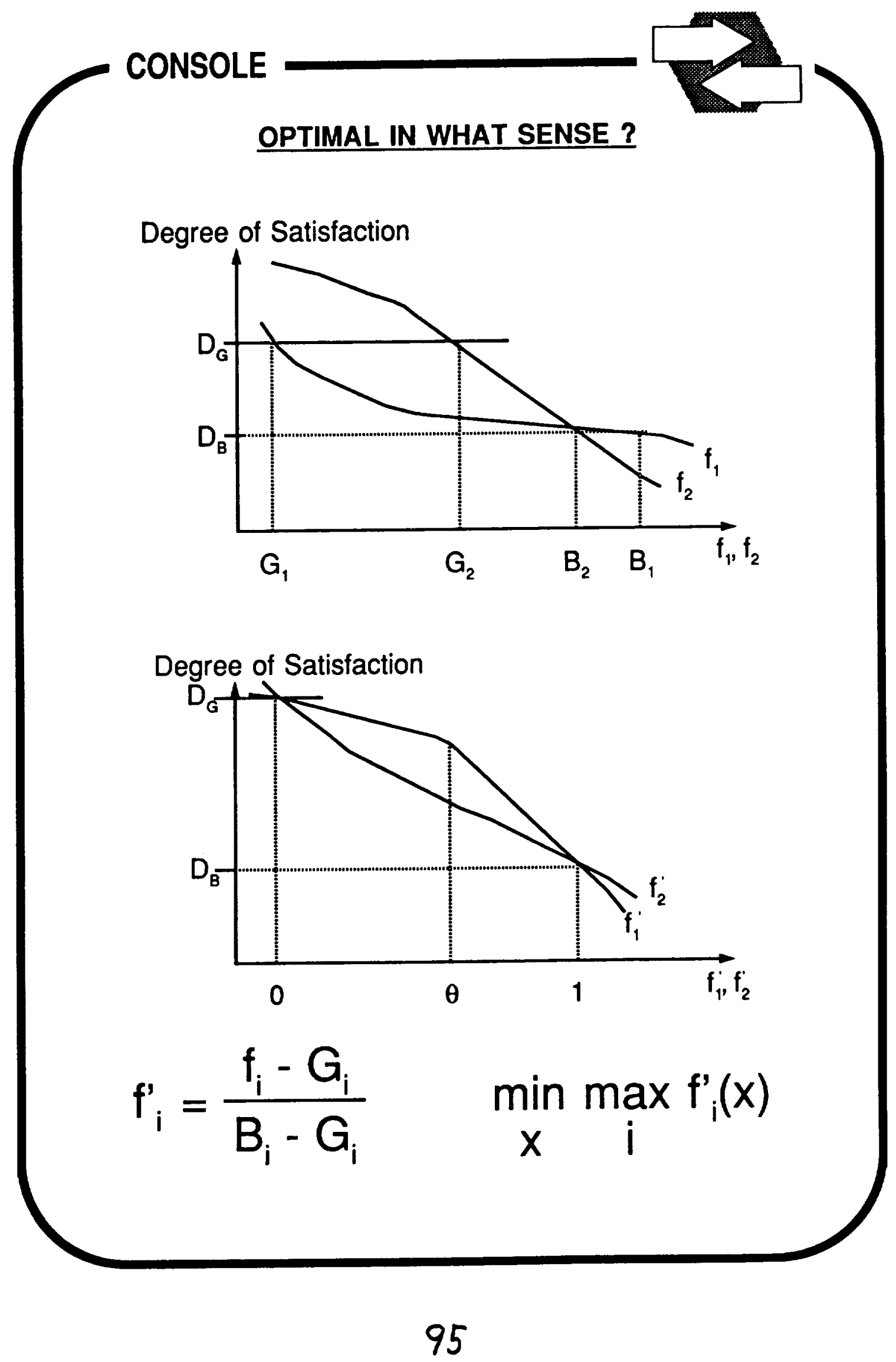




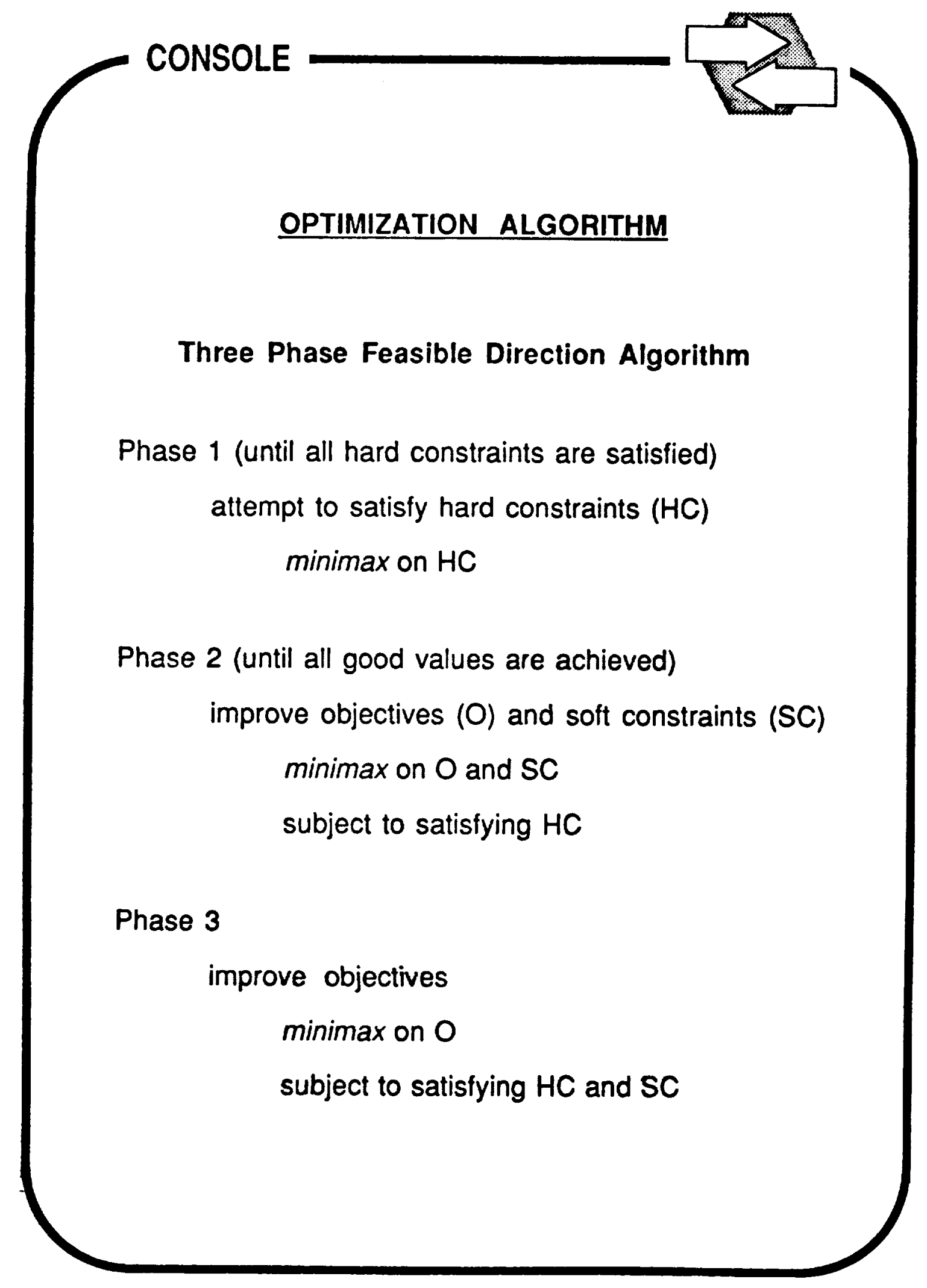




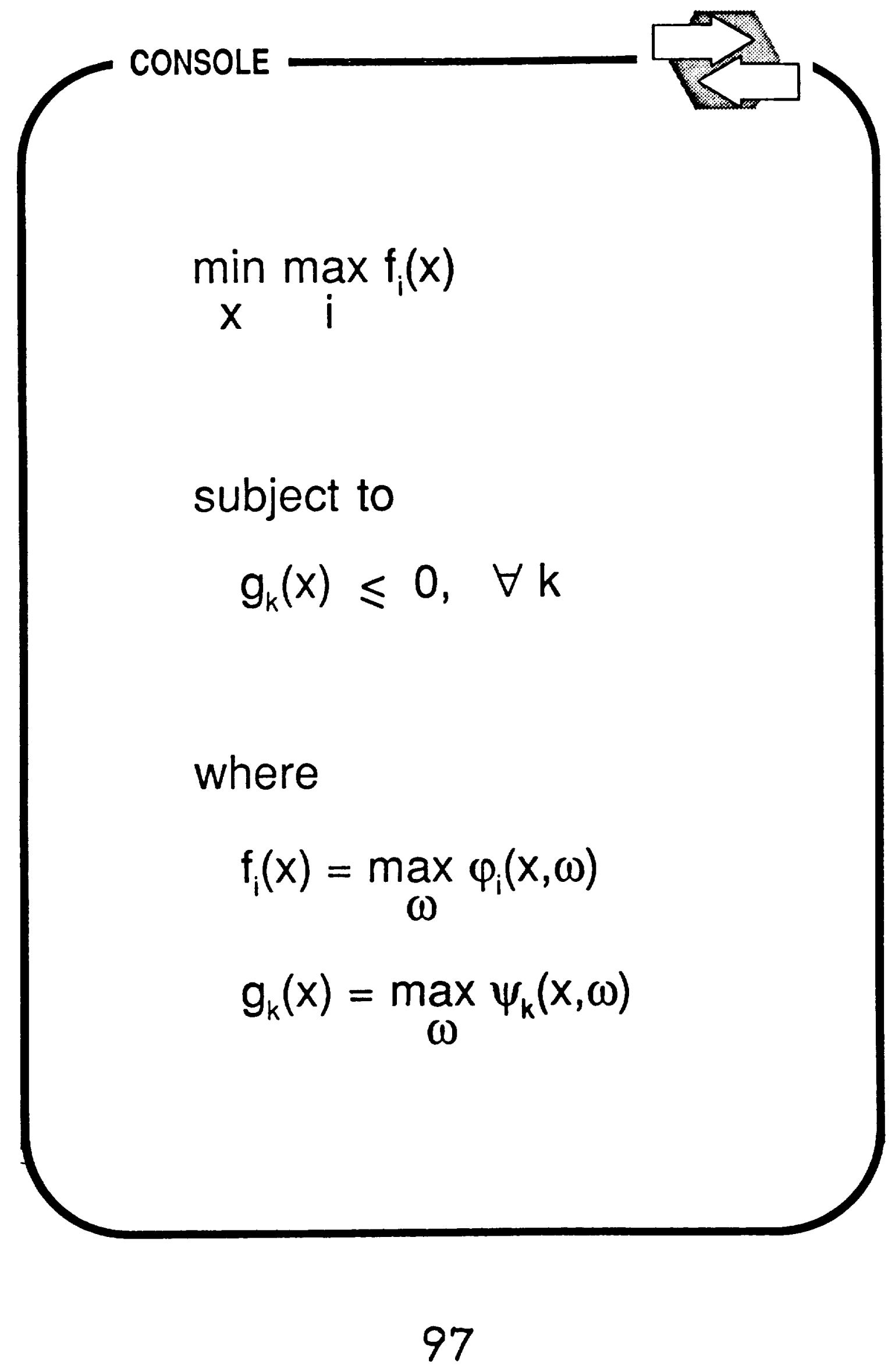




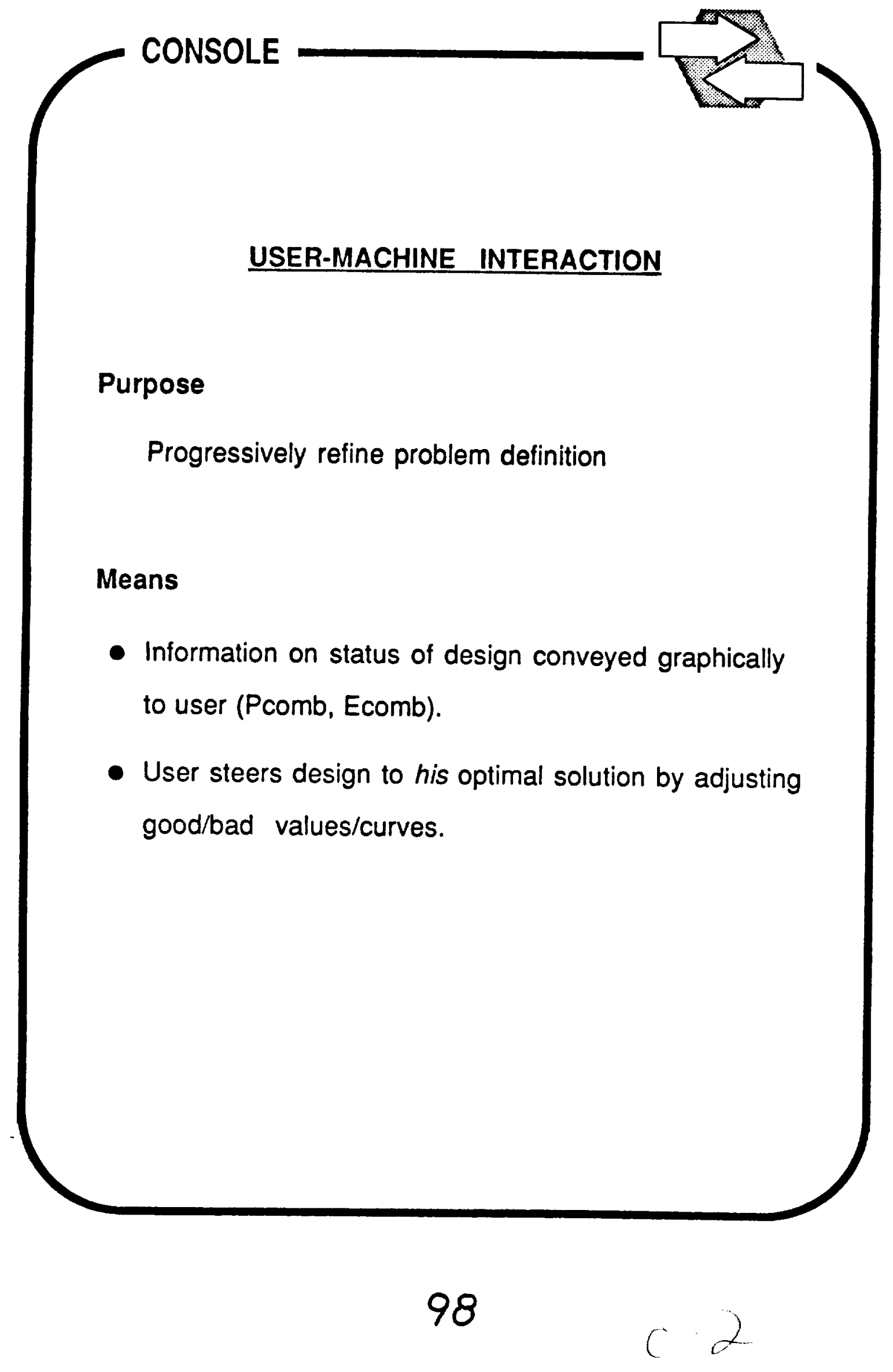




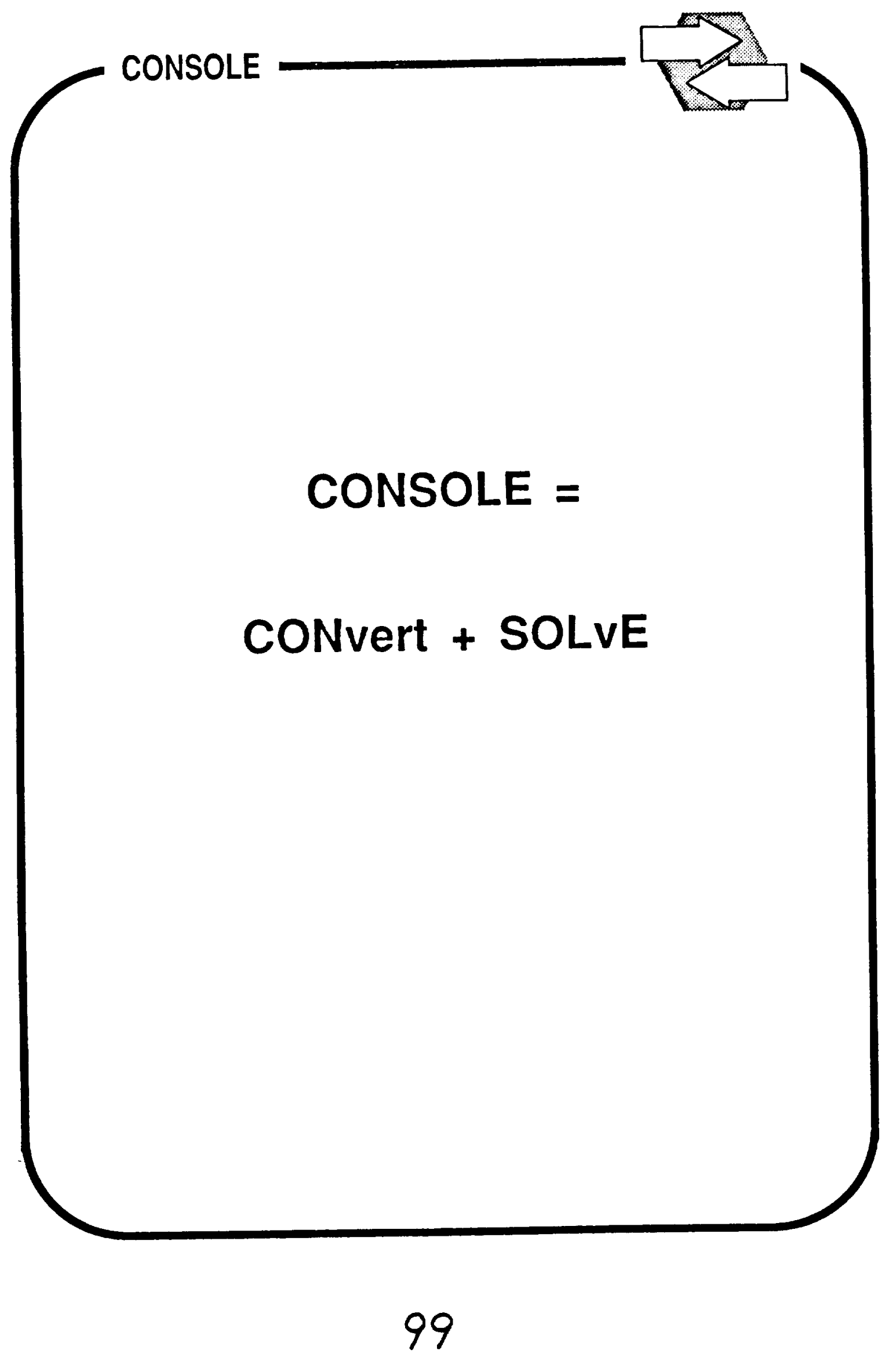




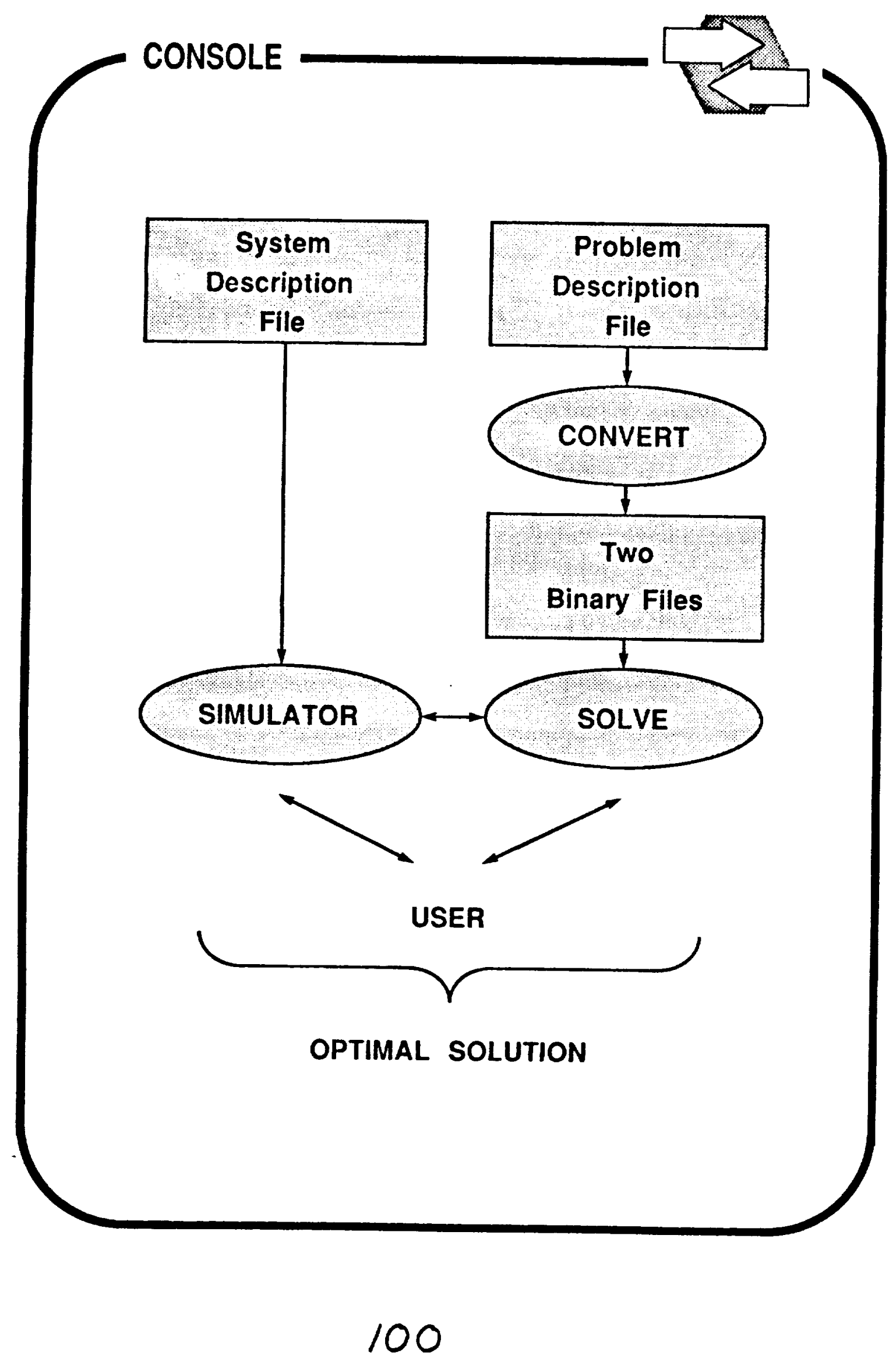




\section{CONSOLE}

\section{A SIMPLE DESIGN EXAMPLE}

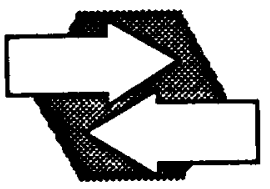

CONTROL SYSTEM

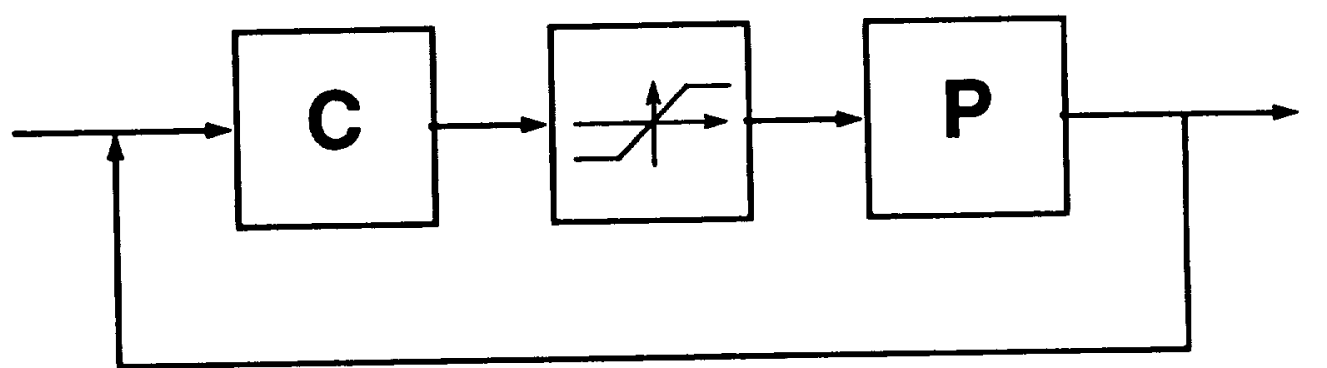

$C(s)=K_{p}+\frac{K_{1}}{s} \quad P(s)=\frac{s+1}{s^{2}}$

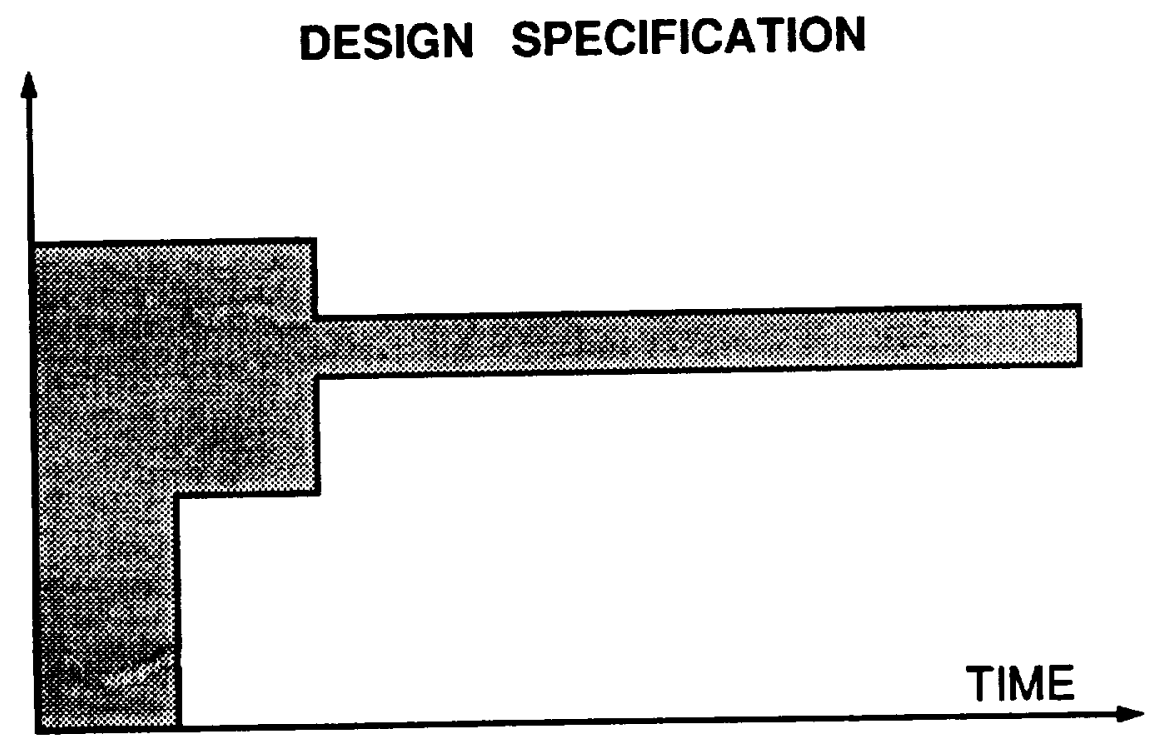




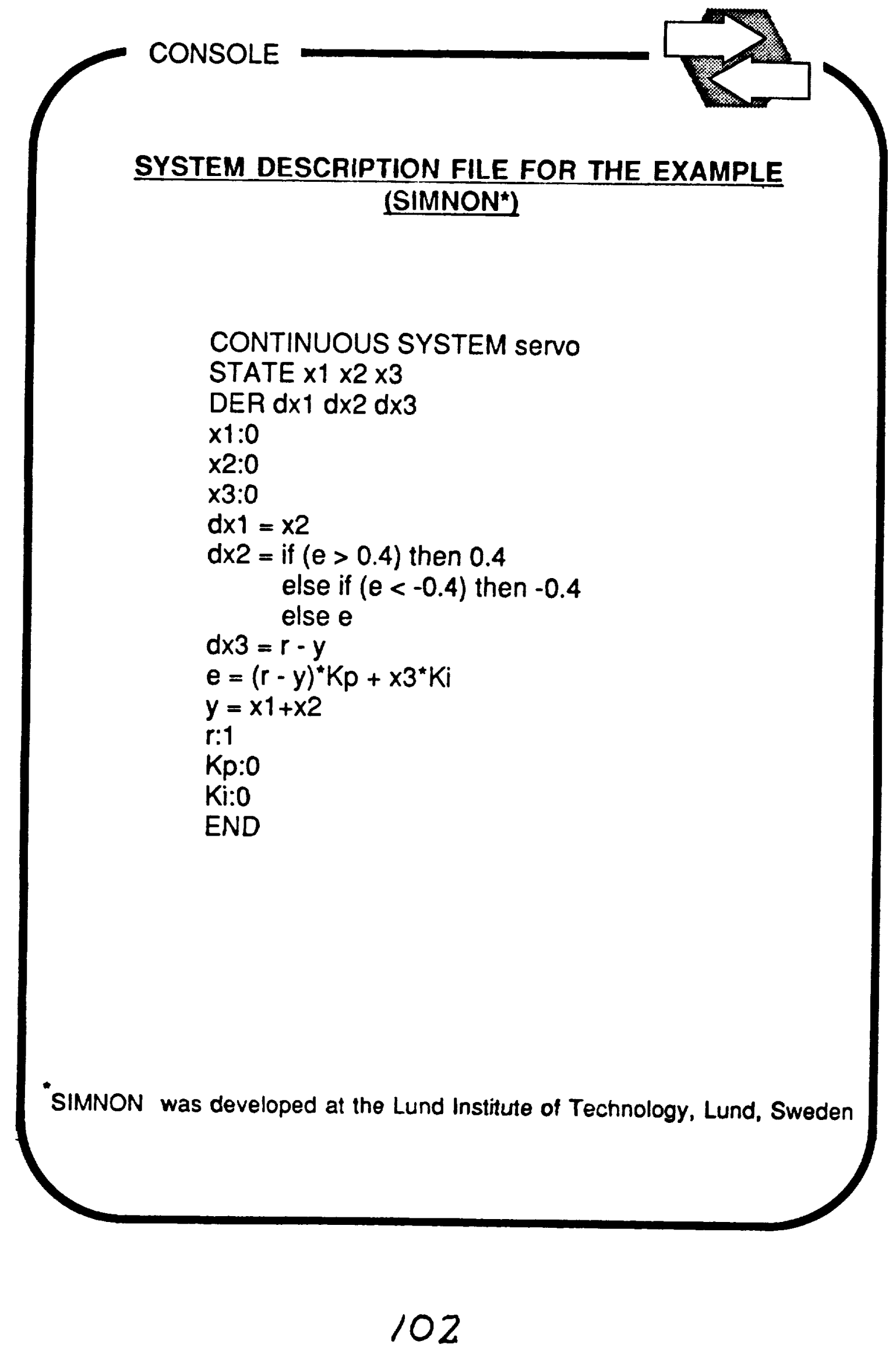




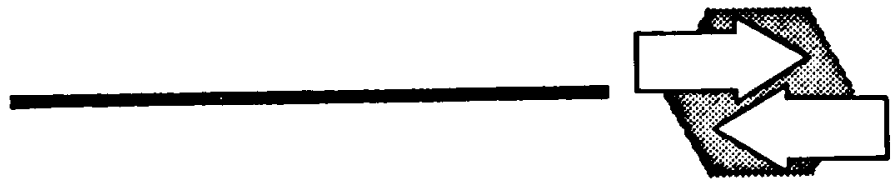

PROBLEM DESCRIPTION FILE FOR THE EXAMPLE

design_parameter $\mathrm{Kp}$ init $=1$ variation $=5$

design_parameter $\mathrm{Ki}$

functional_objective "overshoot"

for $t$ from 0 to 20 by 0.1

minimize \{

double simnon_time_response();

return simnon_time_response(Kp,Ki, "y",t);

1

good_curve $=\{$

if $(t<=4)$ return 1.05;

else return 1.01;

\}

bad_curve $=\{$

if $(t<=4)$ return 1.1 ;

else return 1.02;

\}

functional_objective "settling time"

for $t$ from 2 to 20 by .1

maximize \{ 


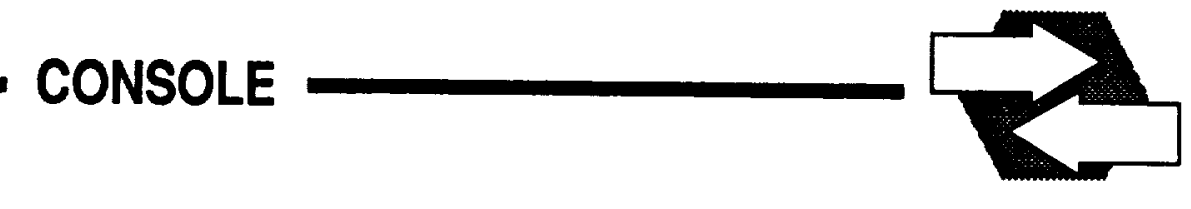

\section{MAIN FEATURES OF CONSOLE}

Problem formulation is closely related to the character of a design problem.

Problem formulation syntax is strict, but easy to use.

Efficient iteration between CONVERT and user for debugging the PDF.

SOLVE is interactive, with short and clearly defined commands providing efficient communication between the program and the user.

Interactive graphics provide the user with easy-to-interpret information on the current design (Pcomb, Ecomb).

User-supplied simulators can easily be linked with SOLVE. 


\section{CONSOLE}

\section{GLANCE AT APPLICATIONS}

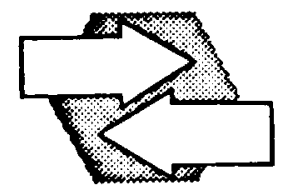

Design of a copolymerization reactor controller (Butala, Choi, Fan)

Design of controllers for a flexible arm

(Wang, Krishnaprasad)

Design of a controller for a robotic manipulator (Chen, Krishnaprasad)

$\mathrm{H}$-infinity Design of a Sampled-Data Control Systems (Yang, Levine)

Solution of a parameter selection problem for a neural network

(Pati, Krishnaprasad et al.)

Design of an RC controller for a radar antenna (Emad)

Design of power filters (Glover, Walrath at Westinghouse Defense and Electronics Center)

... and soon

Design of earthquake proof buildings (Austin)

Design of controllers for $\times 29$ aircraft (Reilly, Levine)

Design of circuits (Westinghouse) 


\section{CONSOLE}

\section{DESIGN OF A COPOLYMERIZATION}

REACTOR CONTROLLER

(CONSOLE + Copoly) (Butala, Choi, Fan)

Objectives and Constraints

Molecular Weight

Composition

Final Volume

Temperature

Feed Flowrate

Manipulated Variables

Temperature $=a_{1}+a_{2} t+a_{3} t^{2}+a_{4} t^{3}$

Feed Flowrate $=b_{1}+b_{2} t+b_{3} t^{2}+b_{4} t^{3}$

Design Parameters $=a_{i}^{\prime}$ s and $b_{i}^{\prime} s$

Results

Pcoub (Iter= 22) (Phese 2) (max_CO5T_SoTT= 0.0766327)

\begin{tabular}{|c|c|c|c|c|c|c|}
\hline \multicolumn{2}{|c|}{ SPECIFICATION } & PRESEMT & COOD & G & $\mathbf{B}$ & DAD \\
\hline 501 & $(m N-m N s)-2$ & $1.920 \cdot 06$ & $0.00 \cdot+00$ & 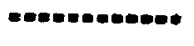 & I & $2.80 \bullet+07$ \\
\hline 502 & $\left(c c-c c_{s}\right)-2$ & $3.88 v-03$ & $0.00 a+00$ & 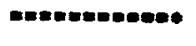 & 1 & $5.06 \bullet-02$ \\
\hline C1 & Pinal rol & $3.47 \bullet+\infty 0$ & $4.000+00$ & e- & $\mathbf{I}$ & $4.100+\infty$ \\
\hline PCI & Dpper seap & $3.53 \bullet+02$ & $3.63 \bullet+02$ & $<-$ & 1 & $3.640+02$ \\
\hline $\mathrm{PC2}$ & lover temp & $3.450+02$ & $3.280+02$ & 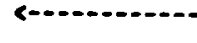 & 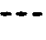 & $3.230+02$ \\
\hline c3 & upper 1108 & $0.700-03$ & $7.000-02$ & $\ll$ & 1 & $7.80-02$ \\
\hline & 101021200 & $6.000-03$ & $0.000+\infty 0$ & & & $-5.000-0$ \\
\hline
\end{tabular}




\section{CONSOLE}

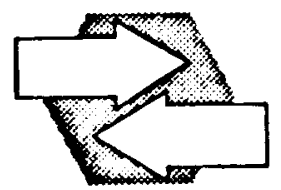

DESIGN OF A DC DIRECT DRIVE MOTOR

(CONSOLE + Simnon) (Wang, Krishnaprasad)

Objective

Position Profile

Design Parameters

Feedback Gains

Results

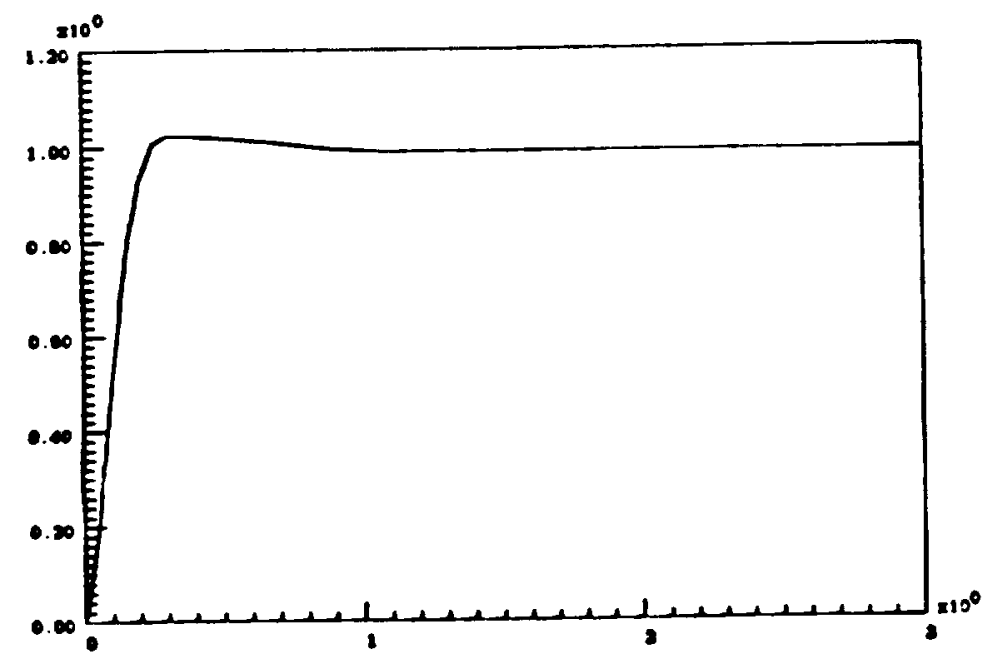




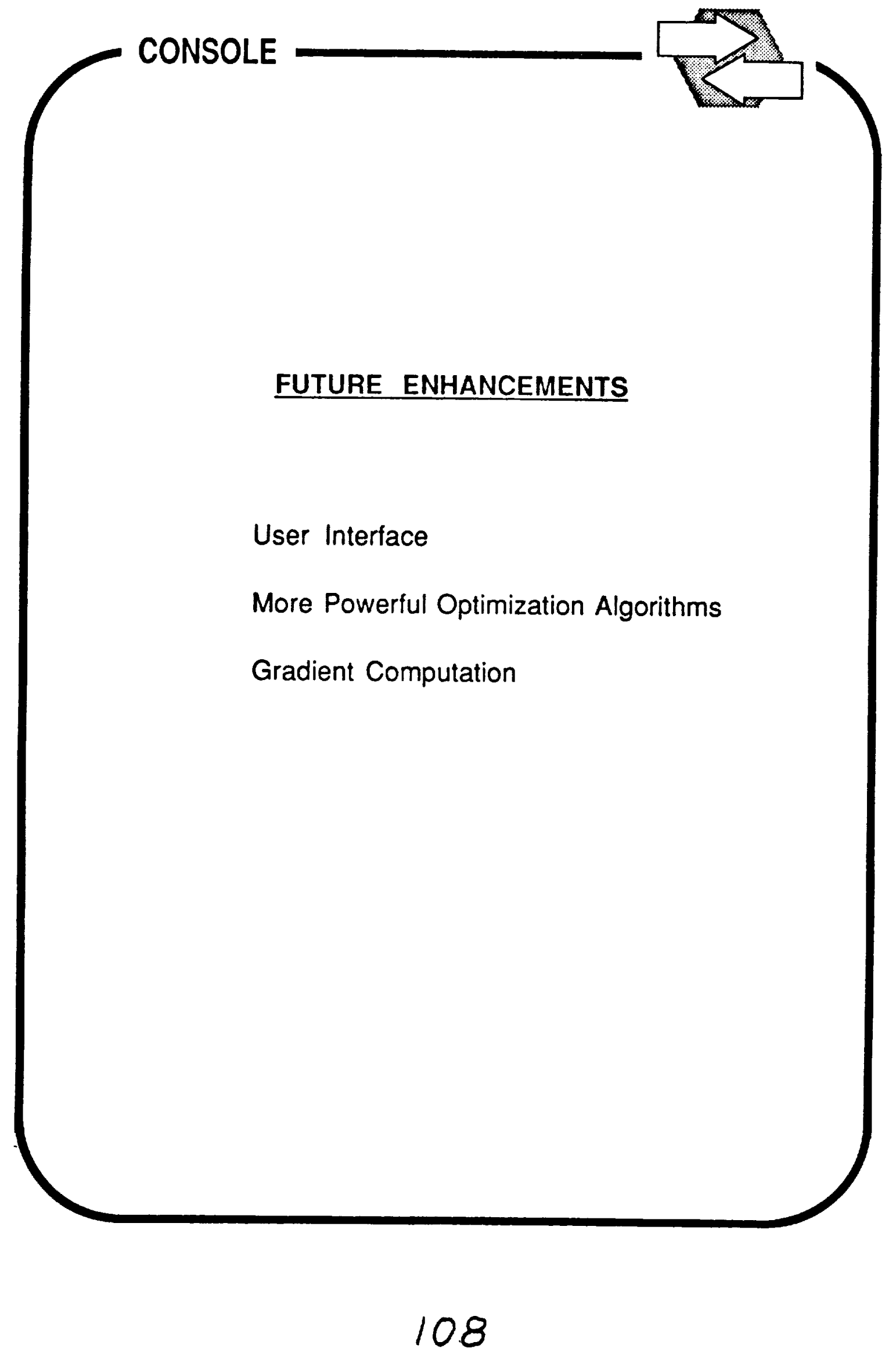

